\title{
Hipercalcemia humoral secundaria a carcinoma mixto de endometrio
}

\section{Humoral hypercalcemia in mixed endometrial carcinoma}

\section{Pinal-Fernández}

\section{RESUMEN}

La hipercalcemia secundaria a enfermedad neoplásica es una entidad frecuente causada en la mayor parte de los casos por secreción ectópica de PTHrp. A pesar de esto hay ciertos tumores, como los carcinomas uterinos, en donde este tipo de manifestación paraneoplásica está muy poco descrita. Presentamos un caso de hipercalcemia humoral en un carcinoma mixto de endometrio.

Palabras clave. Hipercalcemia. Proteína relacionada con la hormona paratifoidea. Neoplasias uterinas. Síndromes paraneoplásicos.

\begin{abstract}
Hypercalcemia secondary to neoplastic disease is a frequent entity caused in the majority of cases by ectopic secretions of PTHrP. Despite this there are certain tumours, such as uterine carcinomas, in which this type of paraneoplastic manifestation has been described very little. We present a case of humoral hypercalcemia in a mixed endometrial carcinoma.
\end{abstract}

Key words. Hypercalcemia. Parathyroid hormone-related protein. Endometrial neoplasms. Paraneoplastic syndromes.
Servicio de Medicina Interna. Hospital Universitario Vall d`Hebrón. Barcelona.

Recepción el 4 de marzo de 2010

Aceptación provisional el 30 de abril de 2010

Aceptación definitiva el 11 de mayo de 2010

\section{Correspondencia}

Iago Pinal-Fernández

Servicio de Medicina Interna

Hospital Universitario Vall d’Hebrón

Torrent de l’Olla, 39-2 $2^{\circ} 2^{\text {a }}$

08012 Barcelona

E-mail: iagopf@yahoo.es 


\section{INTRODUCCIÓN}

La hipercalcemia secundaria a enfermedad neoplásica es una complicación frecuente, presente en el $20-30 \%$ de los pacientes oncológicos a lo largo de su enfermedad y en el $58 \%$ de aquellos ingresados ${ }^{1}$, y de pronóstico ominoso, con una mortalidad del $50 \%$ a los 30 días. Los procesos más comúnmente asociados a hipercalcemia son los cánceres de mama y pulmón, así como el mieloma múltiple ${ }^{2}$.

La hipercalcelmia puede producirse por cuatro mecanismos básicos ${ }^{2}$. La invasión local del hueso por metástasis puede producir la liberación de citoquinas que, actuando de forma paracrina, aumentan la reabsorción ósea y, como consecuencia, el calcio iónico en el torrente sanguíneo. La secreción de vitamina $\mathrm{D}$ por el tumor, mecanismo prácticamente exclusivo de los linfomas, produce una doble acción hipercalcemiante, aumentando la absorción intestinal de calcio y estimulando la reabsorción ósea. La síntesis de hormona paratiroidea (PTH) por el tumor primario es un mecanismo raro que sólo se ha documentado hasta la fecha en 8 pacientes con neoplasias de diferente origen. Por último, el mecanismo más importante, suponiendo cerca del $80 \%$ de las hipercalcemias asociadas al cáncer, es el producido por secreción del péptido relacionado con la parathormona (PTHrp) o hipercalcemia humoral.

\section{CASO CLÍNICO}

Paciente de 83 años de edad con antecedentes personales de hipertensión arterial y un carcinoma de endometrio mixto, endometrioide y de células claras, en estadío T1N0M0, que se detectó un año antes del ingreso actual a raíz de metrorragias. La paciente se sometió a una histerectomía con anexectomía bilateral y linfadenectomía pélvica, completando el tratamiento con braquiterapia adyuvante, que se finalizó 5 meses antes del ingreso actual. Acudía a controles en consultas externas de oncología ginecológica estando hasta la fecha libre de enfermedad.

$\mathrm{Al}$ ingreso presenta astenia, anorexia y debilidad progresivas de dos semanas de evolución, desorientación y bradifasia de 2 días de evolución además de estreñimiento, poliuria, nicturia y polidipsia. En una analítica de control de su centro de atención primaria presenta una calcemia de $15,35 \mathrm{mg} / \mathrm{dL}$ (valores de referencia [v.r.] entre $8,8 \mathrm{mg} / \mathrm{dL}$ y $10,2 \mathrm{mg} / \mathrm{dL}$ ).

En urgencias se realiza una analítica que muestra una calcemia de $16,1 \mathrm{mg} / \mathrm{dL}$ con un calcio iónico de $6,3 \mathrm{mg} / \mathrm{dL}$ (v.r. entre $4,2 \mathrm{mg} / \mathrm{dL}$ y 5,4 $\mathrm{mg} / \mathrm{dL}$ ), con una exploración física, radiografía de abdomen y electrocardiograma normales.

Se diagnostica de síndrome hipercalcémico y se trata con rehidratación, zoledronato intravenoso y furosemida, disminuyendo la calcemia hasta valores normales entre el tercer y el sexto día de tratamiento ${ }^{3,4}$.

La paciente ingresa en la planta de medicina interna donde se objetiva: VSG $106 \mathrm{~mm} / \mathrm{h}$, albúmina $3,16 \mathrm{~g} / \mathrm{dL}$, PTH 21,5 pg/mL (v.r. entre $7 \mathrm{pg} /$ $\mathrm{mL}$ y $82 \mathrm{pg} / \mathrm{mL}$ ), 25-hidroxivitamina D3 $9,9 \mathrm{ng} / \mathrm{mL}$ (v.r. entre $6,6 \mathrm{ng} / \mathrm{mL}$ y $46,4 \mathrm{ng} / \mathrm{mL}$ ) con marcadores tumorales negativos.

Ante el antecedente personal de neoplasia uterina de la paciente se solicita una gammagrafía ósea, que es normal, y un TAC torácico y abdominal que muestra una masa en fondo de saco de Douglas de $10 \mathrm{~cm}$ x $8 \mathrm{~cm}$ con implantes tumorales peritoneales y metástasis pulmonares. Se realiza una biopsia transvaginal de la masa en fondo de saco de Douglas y se confirma una recidiva de su enfermedad neoplásica. La paciente actualmente está en un centro de cuidados paliativos.

\section{DISCUSIÓN}

El síndrome de hipercalcemia humoral clásicamente se caracteriza por exceso de calcio sérico, ausencia de metástasis óseas y concentraciones bajas de $\mathrm{PTH}^{5}$. Para el diagnóstico etiológico de este síndrome debe determinarse la PTHrp. Su determinación puede ser útil para aclarar el pronóstico de la enfermedad y la respuesta al tratamiento médico (empeoran de forma directamente proporcional a la concentración sérica de PTHrp), así como para determinar la probabilidad de recidiva de la hipercalcemia (aumenta con la concentración de PTHrp) ${ }^{6}$. Sin embargo, muchas veces esta determinación no aporta beneficios prácticos dado que lo avanzado del estadio en que la enfermedad suele presentarse cuando aparece esta manifestación hace que el pronóstico sea claro y la única terapia a adoptar sean los cuidados paliativos. 
En la revisión bibliográfica se han encontrado 6 casos de neoplasias uterinas que producen hipercalcemia humoral, un caso de carcinoma papilar seroso, uno de leiomiosarcoma, uno de carcinoma endometrioide y 3 de carcinoma de células claras pero, hasta donde el autor sabe, éste es el primer caso de tumor endometrial mixto descrito en la literatura ${ }^{1,5,7-10}$. La baja prevalencia de hipercalcemia tumoral en el útero podría indicar la existencia de factores locales represores de la expresión o secreción de PTHrp en el útero. Curiosamente, de las 6 neoplasias descritas en 5 de ellas se produjo la hipercalcemia humoral en una recidiva de la enfermedad, lo que indica que para que se produzca se necesita un alto grado de desdiferenciación celular.

\section{Agradrecimientos}

Al Dr. Guardia, al Dr. Viladomiu, a la Dra. Simón-Talero, a la Dra. Malpica, a la Dra. Montoro y al Dr. García por su contribución al diagnóstico. A MA Fernández, M Casal y al Dr. Pérez por su revisión crítica. A nuestra paciente.

\section{BIBLIOGRAFÍA}

1. Savvari P, Peitsidis P, Alevizaki M, Dimopollos MA, Antsaklis A, Papadimitriou CA. Paraneoplastic humorally mediated hypercalcemia induced by parathyroid hormone-related protein in gynecologic malignancies: a sistematic review. Onkologie 2009; 32; 517-523.

2. Stewart AF. Hypercalcemia associated with cancer. N Engl J Med 2005; 352: 373-379.
3. Guía clínica en formato electrónico. Murphy KC, Nakashima L, Kong K. BCCA Protocol summary guidelines for the diagnosis and management of malignancy related hypercalcemia. 2009; 1(1) (consultado 09-052010). Disponible en: http://www.bccancer. bc.ca/NR/rdonlyres/8E898B5D-3F12-46238E32-5B3C429C58F7/34090/SCHYPCAL_ Protocol_1May09.pdf

4. Guía clínica en formato electrónico. Colwell B, Reyno L, White D. Guidelines for the use of zoledronic acid for the treatment of tumor induced hypercalcemia QEII Health Sciences Centre/Cancer Care Nova Scotia. 2001; 1(1) (consultado 09-05-2010). Disponible en: www.cancercare.ns.ca/site-cc/media/cancercare/ZoledronicAcid_Hypercalcemia_dg.pdf

5. Hiller N, Sonnenblick M, Hershko C. Paraneoplastic hypercalcemia in endometrial carcinoma. Oncology 1989; 46; 45-48.

6. Horwitz MJ. Hypercalcemia of malignancy. Uptodate versión 18.1 Monografía en formato electrónico 2010 (consultado 24-5-2010). Disponible en www.uptodate.com

7. Hutchesson A, Dunne F, Bundred NJ, Gee H, RatCLIFFE WA. Parathyroid hormone-related protein as a tumour marker in humoral hypercalcemia associated with occult malignancy. Postgrad Med J 1993; 69: 640-642.

8. Sachmechi I, Kalra J, Molho L, Chawla K. Paraneoplastic hypercalcemia associated with uterine papillary serous carcinoma. Gynecol Oncol 1995; 58: 378-382.

9. Tang S, Geevarghese S, SaAb S, Martínez D, Van Herle A,Wallace WD et al. A parathyroid hormone-related protein-secreting metastatic epithelioid leiomyosarcoma: case report and review of the literature. Arch Pathol Lab Med 2003; 127: e181-185.

10. Kinugasa Y, Morishige K, Kamiura S, Tsukamoto Y, SAJI F. Parathyroid hormone-related proteinsecreting uterine endometrioid adenocarcinoma. Jpn J Clin Oncol 2006; 36: 113-115. 
